Z. Klin. Chem. Klin. Biochem.

13. Jg. 1975 , S. $183-185$

\title{
Freie Fettsäuren und Kohlenwasserstoffe im Liquor cerebrospinalis
}

\author{
Von J. Müller und H. Vahar-Matiar
}

\author{
Abteilung für Liquorphysiologie und klinische Neurochemie (Leiter: Prof. Dr. H. Vahar-Matiar) Univ. Nerven- \\ klinik und Poliklinik (Direktor: Prof. Dr. H. J. Weitbrecht $\dagger$ ) der Universität Bonn
}

(Eingegangen am 24. Mai 1974/14. Februar 1975)

\begin{abstract}
Es werden die ersten Ergebnisse über das konstante Vorkommen von freien Fettsäuren und Kohlenwasserstoffen im Liquor cerebrospinalis mitgeteilt. Mit der hier entwickelten Untersuchungsmethode gelingt es, dicse beiden Substanzgruppen in ausnahmslos allen von uns untersuchten Liquores nachzuweisen. Durch Gaschromatographie in Verbindung mit Massenspcktrometrie ließ sich die Konstitution sowohl der freien Fettsäuren als auch der Kohlenwasserstoffe aufklären. Das dabei gefundene Fettsäurespektrum läßt die Annahme zu, daß es sich hierbei nicht um Serumbeimengungen handelt. Die relative Konstanz des Anteils freier Fettsäuren am Gesamtlipid läßt es auch als unwahrscheinlich erscheinen, daß es sich hierbei um Abbauprodukte aus Phosphatiden bzw. Glykolipiden handelt. Die Herkunft und Bedeutung der Kohlenwasserstoffe konnte in der vorliegenden Arbeit nicht abgeklärt werden und bleibt weiteren Untersuchungen vorbehalten.
\end{abstract}

\section{Free fatty acids and hydrocarbons in cerebrospinal fluid}

Initial experiments on the constant appearance of unesterified fatty acids and hydrocarbons in cerebrospinal fluid are presented. With the present method of analysis, these two groups of substances can always be detected in cerebrospinal fluid. The constitution of the unesterified fatty acids as well as the hydrocarbons was determined using gaschromatography linked to mass spectrometry. There is no evidence that the unesterified fatty acids are derived from the blood, or that they are breakdown products of other lipid classes of the cerebrospinal fluid. The origin and significance of the hydrocarbons are not yet known, and remain the subject of further investigations.

Bei unseren Untersuchungen über die Zusammensetzung der Lipide im Liquor cerebrospinalis konnten wir bereits feststellen, daß außer Phospholipiden, Glykolipiden, freiem und verestertem Cholesterin sowie sehr kleinen Mengen an Triglycerid konstant zwei weitere mit Chloroform:Methanol aus dem Liquor extrahierbare Substanzen auftraten. Schon die ersten dünnschichtchromatographischen Untersuchungen ließen den Schluß zu, daß es sich hierbei um zwei Stoffklassen sehr unterschiedlicher Polarität handelte. Mit Hilfe von Referenzsubstanzen und verschiedenen Färbemethoden äußerten wir schließlich die Vermutung (1), daß es sich bei diesen beiden Stoffklassen um freie Fettsäuren und Kohlenwasserstoffe handeln müsse.

\section{Methodik \\ Untersuchungsmaterial}

Untersucht wurden $4 \times 500 \mathrm{ml}$ Sammelliquor. Die Ergebnisse sind arithmetische Mittelwerte aus diesen vier Untersuchungen. Eine statistische Absicherung war wegen der geringen $\mathrm{Zahl}$ der Proben noch nicht möglich. Die Schwierigkeit erklärt sich daraus, eine genügend große Menge von normalem Sammelliquor zu erhalten. Der Sammelliquor setzt sich zusammen aus Einzelportionen, die von Patienten gewonnen wurden, die im Rahmen einer gutachtlichen Untersuchung in unserer Klinik pneumoencephalographiert wurden und bei denen keine neurologische Erkrankung nachgewiesen werden konnte. Außerdem wurde
Liquor von Patienten verwendet, die nach einem Grand-malAnfall in die Klinik kamen und im Rahmen der neurologischen Untersuchung ebenfalls pneumoencephalographiert wurden. Bei diesen Patienten handelte es sich ausschließlich um solche, bei denen die Diagnose einer genuinen Epilepsie gestellt wurde und die keine neurologischen Auffälligkeiten aufwiesen. Außerdem wurde der Liquor solcher Patienten untersucht, bei denen die Manifestation der Anfallserkrankung nicht länger als ein halbes Jahr zurücklag und die in diesem Zeitraum nicht mehr als drei große Anfälle erlitten hatten.

Weiterhin wurde darauf geachtet, daß der Liquor hinsichtlich Zellzahl, Eiweißgehalt, Mastixkurve und Liquorelektrophorese keine Besonderheiten aufwies.

Der so gewonnene Sammelliquor wurde bei $50^{\circ} \mathrm{C}$ unter Stickstoff eingeengt. Anschließend wurde zwei mal mit $50 \mathrm{ml} \mathrm{Chlo-}$ roform-Methanol (Volumina, $80 \mathrm{ml}+50 \mathrm{ml}$ ) extrahiert. Der gewonnene Chloroform-Methanol-Extrakt wurde ebenfalls unter Stickstoff bei $50^{\circ} \mathrm{C}$ auf $5 \mathrm{ml}$ eingeengt und dann auf drei selbst hergestellte Dünnschichtplatten aufgetragen.

Herstellung der Dünnschichtchromatographie-Platten

$20 \times 20 \mathrm{~cm}$ große Platten wurden vor Gebrauch in ChromSchwefelsäure gesäubert. Zur Beschichtung der Platten verwendeten wir Kieselgel Mn. Hr. der Fa. Machery und Nagel. Dieses Kieselgel weist nach unseren Erfahrungen gute Trenneigenschaften auf und braucht nicht vorgereinigt zu werden. Zur Kontrolle haben wir $10 \mathrm{~g}$ Kieselgel mit $50 \mathrm{ml}$ Chloroform-Methanol (Volumina, $80 \mathrm{ml}+50 \mathrm{ml}$ ) extrahiert, diesen Extrakt eingeengt und anschließend nach 1. c. (1) untersucht. Dabei fand sich lediglich unmittelbar an der Lösungsmittelfront eine leichte Verunreinigung. Lipide oder Kohlenwasserstoffe waren jedoch nicht nachweisbar.

Für die Herstellung von 5 Platten benötigten wir $60 \mathrm{~g}$ Kieselgel und $110 \mathrm{~g}$ Wasser. 


\section{Entwicklung der Platten}

Jede Platte wurde anschließend in drei Laufmittelsystemen fallender Polaritiit entwickelt. Dabei läft man das crste Laufmittel (Chloroform: Methanol: Wasser, Volumina $75 \mathrm{ml}+25 \mathrm{ml}+4 \mathrm{ml}$ ) ungefïhr bis $2 \mathrm{~cm}$ übur dic Auftragstelle steigen. Nach kurzem Trocknen an der Luft (etwa $5 \mathrm{~min}$ ) wird in dem zweiten Laufmittel (Chloroform) bis zur Mitte der Platte cntwickelt und anschließend im dritten Laufmittel (Chloroform: $n$-Hexan, Volumina $10 \mathrm{ml}+30 \mathrm{ml}$ ) bis zum Plattenrand.

\section{Detektion}

Zur Identifizierung werden die Platten mit einer alkoholischen Lösung von Natrium-Dichlor-Fluorescein $(10 \mathrm{~g} / \mathrm{l})$ besprüht. Unter UV-Licht kann man dic einzelnen Lipidbanden gut erkennen. Sie stellen sich in folgender Reihenfolge von der Auftragstelle her dar: 1. Phospholipide, 2. Ccrebroside, 3. freie Fettsäuren, 4. Cholesterin, 5. Triglyccride, 6. verestertes Cholesterin, 7. Kohlenwasserstoffe.

Die Fraktionen werden von der Platte gekratzt: die freien Fettsäuren im ersten Laufmittel aufgenommen, die Kohlenwasserstoffe in dem dritten. Anschließend erfolgte nach 1. c. (1) eine Übcrprüfung beider Fraktionen (freie Fettsäuren, Kohlenwasserstoffe) auf Reinheit und Einheitlichkeit. Dabei stellten wir fest, daß beide Fraktionen als Verunreinigung lediglich noch NatriumDichlorfluorescein enthielten. Aus der Fraktion der Kohlenwasserstoffe läßt sich dieses Sprühmittel mit rlilfe von Wasser auswaschen. Dies gelingt jedoch bei der Fraktion der freien Fettsäuren nicht. Hier stört das Vorhandensein des Sprühmittels jedoch nicht, da die Fraktion der freien Fettsäuren im Hochvakuum (Kurzweg-Destillation im Kugelrohr) vor der weiteren gaschromatographischen Untersuchung destilliert wird und dabei das Natrium-Fluorescein zurückbleibt.

Die freien Fettsäuren und die Kohlenwasserstoffe wurden anschließend gaschromatographisch und massenspektrometrisch an einem LKB 9000 analy siert $^{3}$ ).

\section{Leerk ontrollen}

Um sicher zu sein, daß die freien Fettsäuren nicht durch Lipolyse freigesetzt wurden, haben wir frisch entnommenen Liquor unmittelbar nach der Entnahme nach 1. c. (1) extrahiert. Es wurden jeweils $2 \mathrm{ml}$ Liquor $(n=10)$ extrahiert. In allen Liquores konnten wir sowohl freie Fettsäuren als auch Kohlenwasserstoffe nachweisen. Dabei ergab sich ein arithmetischer Mittelwert von $7,1 \%$ an freien Fettsäuren und $6,6 \%$ Kohlenwasserstoffe, bezogen auf extrahierte Substanz.

Um auszuschließen, daß die von uns hier beschriebenen Fraktionen Fremdbeimischungen sind, wurden $2 \times 500$ ml bidest. Wasser mit der in dieser Arbeit beschriebenen Methode bei $50^{\circ} \mathrm{C}$ eingeengt und in gleicher Weise wie der Liquor cerebrospinalis extrahiert. Dünnschichtchromatographisch ließen sich keine Lipide bzw. Kohlenwasserstoffe nachweisen, lediglich unmittelbar an der Lösungsmittelfront fanden sich Verunreinigungen.

Mit den später zur Injektion verwendeten HAMILTON-Spritzen wurden Leereinspritzungen vorgenommen, die gleichzeitig der Hintergrundsmessung des Massenspektrometers dienten. Hierbei wurden weder freie Fettsäuren noch Kohlenwasserstoffe nachgewiesen.

Alle verivendeten Glasgeräte (Pipetten, Schliffröhrchen, Meßkolben) wurden in Chrom-Schwefclsäure gereinigt und mit bidest. Wasser gespült.

\section{Ergebnisse}

Mit der von uns mitgeteilten Methodik (1) fanden wir einen Anteil von 7,3\% freien Fettsäuren, bezogen auf gesamte extrahierte Substanz. Die Tabelle 1 zeigt die

1) Die Untersuchungen wurden freundlicherweise von Herrn Prof. Dr. Egge, Institut f. Physiol. Chemie der Univ. Bonn durchgeführt.
Tab. 1. Freie Fettsäuren im Liquor cerebrospinalis und deren prozentuale Verteilung.

\begin{tabular}{lc}
\hline Fettsäurc & $\begin{array}{l}\text { Anteil } \\
\text { [\% der gesamten } \\
\text { freien Fettsäuren] }\end{array}$ \\
\hline C $12: 0$ & 0,11 \\
C $14: 0$ & 1,43 \\
C $15: 0$ & 0,13 \\
C $16: 0$ & 31,93 \\
C $16: 1$ & 15,13 \\
C $18: 0$ & 23,21 \\
C $18: 1$. & 20,97 \\
C $18: 2$. & 2,8 \\
C $18: 3$. & 0,31 \\
C $20: 0$ & 0,44 \\
C $20: 1$ & 1,28 \\
C $20: 3$. & 0,28 \\
C 20:4 & 1,61 \\
C 22:0 & 0,28 \\
\hline
\end{tabular}

identifizierten Fettsäuren und deren prozentuale Verteilung (arithmetischer Mittelwert aus 4 Messungen). Dabei ist auffallend, daß das Liquorfettsäurespektrum dem Serumfettsäurespektrum keineswegs gleicht. Die Fettsäure C 16:1, die wir im Liquor mit einer Relation von $15,13 \%$ der Gesamtfettsäuren nachwiesen, ist im Serum deutlich niedriger. Auch C 18:0, deren Anteil im Liquor $23,21 \%$ der Gesamtfettsäuren beträgt, ist im Serum nur in einer deutlich niedrigeren Relation vorhanden. C 18:2 und C 20:4 dagegen finden sich im allgemeinen im Serum in einer wesentlich höheren Relation (siehe Tab. 1).

Die Kohlenwasserstoffe machen etwa 6,8\% der unpolaren Substanzen aus, die wir mit Chloroform-Methanol aus dem Liquor extrahierten. Die Gaschromatographie in Verbindung mit Massenspektrometrie ergab drei unterschiedliche Kohlenwas̄serstoffe, und zwar zwei gesättigte mit der Masse $296\left(\mathrm{C}_{21} \mathrm{H}_{44}\right.$ (siehe Tab. 1) und $324\left(\mathrm{C}_{23} \mathrm{H}_{48}\right)$ sowie einen ungesättigten mit der Masse $320\left(\mathrm{C}_{23} \mathrm{H}_{44}\right)$.

\section{Diskussion}

Bei der Durchsicht der bisherigen Arbeiten über das Vorkommen von freien Fettsäuren im Liquor cerebrospinalis finden sich untereinander stark abweichende Angaben. Schrader \& Schwarz (2) konnten weder im normalen Liquor noch bei entzündlichen und degenerativen Erkrankungen des Zentralnervensystems freie Fettsäuren im Liquor nachweisen. Dagegen wurden von Hirai (3) papierchromatographisch freie Fettsäuren bei Patienten mit Encephalitis im Beginn der Erkrankung gefunden. Schließlich wies Nischi (4) Buttersäure auf papierchromatographischen Wege bei der Encephalitis japonica nach. Bei anderen entzündlichen und degenerativen Veränderungen konnte dieser Autor freie Fettsäuren im Liquor cerebrospinalis nicht nachweisen: Illingworth \& Glover (5) hatten ebenfalls nur in einigen der von ihnen untersuchten Liquores bei Kindern und Erwachsenen 


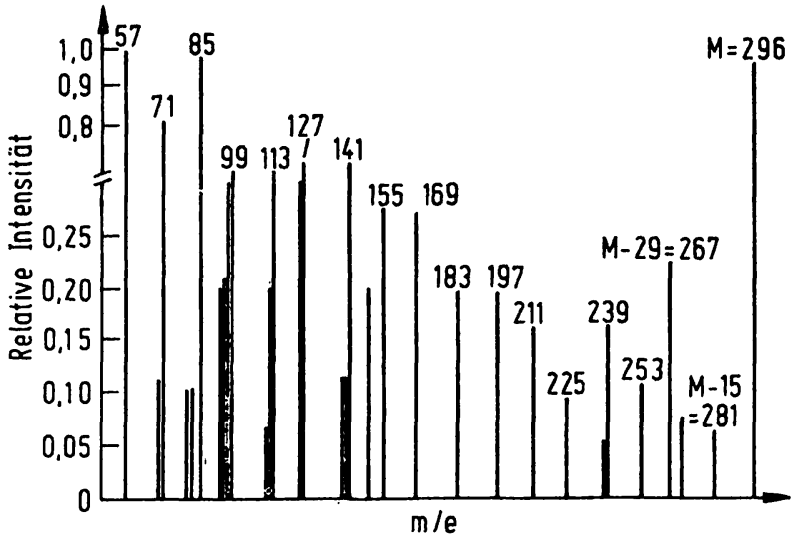

Abb. 1. Massenspektrum der Kohlenwasserstoffe mit der Masse 296.

unveresterte Fettsäuren gefunden, wobei die Ausbeute bei den Liquores mit hohem Eiweißgehalt größer war.

Pilz (6) dagegen schreibt, daß die freien Fettsäuren ähnlich wie das im Liquor nachgewiesene Cholin, wie auch Inosit, Äthanolamin, Serin und Neuraminsäure möglicherweise als Lipidabbauprodukte aufgefaßt werden könnten. Schrappe führt in seiner Übersicht über die im Liquor vorkommenden Lipide (7) die freien Fettsäuren nicht auf.

In dieser Arbeit konnte die Herkunft der freien Fettsäuren im Liquor noch nicht geklärt werden. Die freien Fettsäuren könnten als Lipidabbauprodukte aufgefaßt werden, wobei an eine Genese aus den Triglyceriden oder aus den Phospho- bzw. Glykolipiden zu denken wäre. Doch läßt sich die Möglichkeit, daß die von uns gefundenen freien Fettsäuren als Abbauprodukte aus Triglyceriden entstanden sind, durch unsere Untersuchungen nahezu mit Sicherheit ausschließen, denn in einem solchen Falle hätten wir auch Mono- und Diglyceride nachweisen müssen. Das ist jedoch nicht in einem einzigen Falle geschehen. Aber auch der anderen Auffassung, daß es sich bei den freien Fettsäuren um Abbauprodukte. aus Phospho- und Glykolipiden handelt, können wir uns vorerst nicht anschließen. Hiergegen spricht $u$. a. auch die relative Konstanz von etwa
7\% Anteil der freien Fettsäuren am Gesamtlipid. Sowohl bei frisch entnommenen und unmittelbar aufgearbeiteten Liquorproben wie auch bei Liquor, der längere Zeit um $-25^{\circ} \mathrm{C}$ aufbewahrt wurde, trat keine wesentliche Änderung am prozentualen Anteil der freien Fettsäuren an der Gesamtlipidmenge auf.

Die Annahme, daß die im Liquor cerebrospinalis aufgetretenen freien Fettsäuren aus dem Serum stammen, etwa aus dem Plexus chorioideus oder den Meningen, läßt sich durch unsere Untersuchungen ebenfalls nicht stützen. Hiergegen spricht bereits das Liquorfettsäurespektrum, welches keinesfalls dem Serumfettsäurespektrum gleicht. Dieses zeigt sich insbesondere an den Säuren C 16:1 und C 18:0, die sich im Serum in einer deutlich geringeren Relation nachweisen lassen oder an den Säuren C 18:2 und C 20:4, deren Relation im Liquor wesentlich geringer als im Serum ist. Hieraus folgert, daß die im Liquor cerebrospinalis nachgewiesenen Fettsäuren keinesfalls durch einen Serumübertritt zu erklären sind, sondern es muß vielmehr angenommen werden, daß es ein spezifisches, dem Liquor zugehöriges Fettsäurespektrum gibt. Illingworth \& Glover (5) hatten bereits darauf hingewiesen, daß offensichtlich in der Fettsäurezusammensetzung der verschiedenen Lipidklassen zwischen Liquor- und Hirnlipiden ein engerer Zusammenhang besteht als zwischen Liquor- und Serumlipiden und hatten dies $u$. a. dadurch erklärt, daß zwischen dem Liquor und dem Hirngewebe ein Austausch stattfindet.

Die Herkunft der Kohlenwasserstoffe, die etwa 7\% der von uns mit Chloroform-Methanol extrahierten unpolaren Substanzen ausmachten, muß vorerst offenbleiben. Durch umfangreiche Kontroll- und Leerversuche glauben wir aber hinreichend sichergestellt zu haben, daß es sich hierbei nicht um eingeschlepptes Fremdmaterial, sondern um authentische Anteile des Liquor cerebrospinalis handelt. Weitere Untersuchungen an Liquores, die an verschiedenen Stellen des Zentralnervensystems entnommen sind (Ventrikelliquor, Suboccipitalliquor und Lumballiquor), vermögen hierüber gegebenenfalls nähere Aufschlüsse zu liefern.

\section{Literatur}

1. Müller, J. \& Vahar-Matiar, H. (1974), Z. Neurol. 206, 333-344.

2. Schrader, A. \& Schwarz, K. (1963), Münch. Med. Wochenschr. 105, 2493-2500.

3. Hirai, T. (1956), J. Jap. Ass. Infect. Dis. 29, 568-576.

4. Nischi, H. (1957), J. Osaka City Med. Center 6, 416.

5. Illingworth, D. R. \& Glover, J. (1971), J. Neurochem. 18, 769-776.

6. Pilz, H. (1970), Die Lipide des normalen und pathologischen Liquor cerebrospinalis. Springer, Berlin-Heidelberg-New York.

7. Schrappe, O. (1968), Forum der Psychiatrie 20, 129-149.

Dr. J. Müller

Prof. Dr. H. Vahar-Matiar

Abtcilung für Liquorphysiologic und klinische Neurochemie

Univ. Nervenklinik Bonn

53 Bonn-Venusberg 


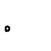

